\title{
Article \\ Effect of Printing Layer Thickness on the Trueness and Margin Quality of 3D-Printed Interim Dental Crowns
}

\author{
Gülce Çakmak ${ }^{1}$, Alfonso Rodriguez Cuellar ${ }^{2}$, Mustafa Borga Donmez ${ }^{3}$ DD, Martin Schimmel ${ }^{1,4}$, \\ Samir Abou-Ayash 1,*(D), Wei-En Lu ${ }^{5}$ and Burak Yilmaz 1,6,7
}

1 Department of Reconstructive Dentistry and Gerodontology, School of Dental Medicine, University of Bern, 3010 Bern, Switzerland; guelce.cakmak@zmk.unibe.ch (G.Ç.); martin.schimmel@zmk.unibe.ch (M.S.); burak.yilmaz@zmk.unibe.ch (B.Y.)

2 Department of Periodontology, Clinica Dental Rodriguez Dental Clinic, Mexico City 03100, Mexico; alfonso_rodriguez@my.unitec.edu.mx

3 Department of Prosthodontics, Biruni University Faculty of Dentistry, 34010 Istanbul, Turkey; bdonmez@biruni.edu.tr

4 Division of Gerodontology and Removable Prosthodontics, University Clinics of Dental Medicine, University of Geneva, 1205 Geneva, Switzerland

5 Division of Biostatistics, The Ohio State University College of Public Health, Columbus, OH 43210, USA; lu.1408@buckeyemail.osu.edu

6 Department of Restorative, Preventive and Pediatric Dentistry, School of Dental Medicine, University of Bern, 3010 Bern, Switzerland

7 Division of Restorative and Prosthetic Dentistry, The Ohio State University College of Dentistry, Columbus, $\mathrm{OH} 43210$, USA

* Correspondence: samir.abou-ayash@zmk.unibe.ch; Tel.: +41-(0)31-632-8705

Citation: Çakmak, G.; Cuellar, A.R.; Donmez, M.B.; Schimmel, M.;

Abou-Ayash, S.; Lu, W.-E.; Yilmaz, B. Effect of Printing Layer Thickness on the Trueness and Margin Quality of 3D-Printed Interim Dental Crowns. Appl. Sci. 2021, 11, 9246. https:// doi.org/10.3390/app11199246

Academic Editor: Kathrin Becker

Received: 8 September 2021

Accepted: 2 October 2021

Published: 5 October 2021

Publisher's Note: MDPI stays neutral with regard to jurisdictional claims in published maps and institutional affiliations.

Copyright: (c) 2021 by the authors. Licensee MDPI, Basel, Switzerland. This article is an open access article distributed under the terms and conditions of the Creative Commons Attribution (CC BY) license (https:// creativecommons.org/licenses/by/ $4.0 /)$.
Abstract: The information in the literature on the effect of printing layer thickness on interim 3D-printed crowns is limited. In the present study, the effect of layer thickness on the trueness and margin quality of 3D-printed composite resin crowns was investigated and compared with milled crowns. The crowns were printed in 3 different layer thicknesses $(20,50$, and $100 \mu \mathrm{m})$ by using a hybrid resin based on acrylic esters with inorganic microfillers or milled from polymethylmethacrylate (PMMA) discs and digitized with an intraoral scanner (test scans). The compare tool of the $3 \mathrm{D}$ analysis software was used to superimpose the test scans and the computer-aided design file by using the manual alignment tool and to virtually separate the surfaces. Deviations at different surfaces on crowns were calculated by using root mean square (RMS). Margin quality of crowns was examined under a stereomicroscope and graded. The data were evaluated with one-way ANOVA and Tukey HSD tests. The layer thickness affected the trueness and margin quality of 3D-printed interim crowns. Milled crowns had higher trueness on intaglio and intaglio occlusal surfaces than $100 \mu \mathrm{m}$-layer thickness crowns. Milled crowns had the highest margin quality, while $20 \mu \mathrm{m}$ and $100 \mu \mathrm{m}$ layer thickness printed crowns had the lowest. The quality varied depending on the location of the margin.

Keywords: 3D printing; additive manufacturing; interim crowns; provisional crowns; trueness; accuracy; layer thickness; margin quality

\section{Introduction}

The introduction of digital technologies into dental practice has facilitated manufacturing, as computer aided design-computer aided manufacturing (CAD-CAM) enabled the fabrication of accurate definitive restorations [1]. CAD-CAM manufacturing can be subtractive (milling) [2] or additive, and the interest has recently shifted towards additive manufacturing technologies that are also known as rapid prototyping or 3-dimensional (3D) printing [3-5].

3D-printing manufactures an object by building up consecutive layers [5,6] and is used for a wide range of dental applications including diagnostic and master models, 
surgical guides, complete dentures, occlusal splints, impression trays, implants, metal crowns, copings, and frameworks [4,7-13]. Printing has certain advantages over milling as less waste material is produced, multiple products with more complex geometries can be fabricated, and less energy is consumed [14,15]. Moreover, due to an increased accuracy and speed, of 3D-printing has increased its popularity in the dental field [16]. Several different 3D-printing technologies, namely stereolithography (SLA), digital light processing (DLP), material jetting (MJ), material extrusion (ME), binder jetting, powder bed fusion $(\mathrm{PBF})$, sheet lamination, and direct energy deposition, are currently available for polymers [7]. However, among these technologies, the popularity of DLP, which is based on the UV light activation of the photosensitive resin [17], is increasing for the fabrication of dental prosthesis $[4,18]$.

Interim restorations are an essential component of the prosthodontic treatment as they act as a prototype of the definitive prosthesis providing esthetics, pulp protection, tooth positional stability, and soft tissue management $[19,20]$. Conventional interim restorations are fabricated commonly by using polymethylmethacrylate (PMMA) due to its accessibility, ease of fabrication and repair, low cost, biocompatibility, and stability in the oral environment [19-21]. Even though direct fabrication of acrylic resin interim crowns is feasible [22], polymerization shrinkage, possible biologic reactions due to the residual monomers, and marginal and occlusal discrepancies can be observed [20,22,23]. The indirect fabrication of these restorations with CAD-CAM technologies led to a better internal fit [20] and marginal integrity [24], enabling successful and long-lasting restorations [20]. Both subtractive manufacturing and 3D-printing technologies are applicable for the fabrication of interim restorations [19].

Efficiency of 3D-printing is affected by the layer thickness, laser intensity, laser speed, build angle, the geometry of the supporting structures, and printing technology [14,21,25-27]. Layer thickness is a controllable parameter that affects the accuracy, which is defined by trueness and precision [28], of the final restoration [7]. Therefore, setting the appropriate layer thickness is crucial to achieve optimum results. In addition, layer thickness was shown to affect the printing speed and printing accuracy [16]. In general, the layer thickness of a 3D-printer based on photopolymerization ranges between 20 to $150 \mu \mathrm{m}$ [7].

Previous studies on 3D-printed interim materials have mainly focused on the effect of printing orientation $[14,18,25,26,29]$, while the effect of layer thickness was assessed primarily when 3D-printed dental models [16], trial dentures [30], and custom trays [13] were printed. Only one study investigated the effect of printing orientation and layer thickness on the fit of 3-unit implant-supported fixed partial dentures [31]. To the authors' knowledge, no study has evaluated the effect of layer thickness on the accuracy of 3D-printed interim crowns. Therefore, the aim of this study was to investigate the trueness and margin quality of interim crowns printed in 3 different layer thicknesses $(20,50$, and $100 \mu \mathrm{m})$ comparing with that of milled PMMA crowns. The null hypotheses were that (i) fabrication technique would not affect the trueness of the crowns and (ii) fabrication technique and margin location would not affect the margin quality of the restorations.

\section{Materials and Methods}

\subsection{Model and Crown Data Acquisition}

A mandibular right first molar tooth in a dentate typodont model (ANA-4, Frasaco $\mathrm{GmbH}$, Tettnang, Germany) was prepared with a 1-mm-wide chamfer finish line to simulate a complete coverage crown preparation. The maxillary and mandibular typodont models and both models when in occlusion were scanned by using an intraoral scanner (Medit i500 v. 1.2.1, Medit, Seoul, Korea) that has a precision of $25 \mu \mathrm{m}$, according to the manufacturers' recommended scan strategy. The scans were converted to standard tessellation language (STL) files (Figure 1). A complete-coverage restoration was designed to simulate an interim crown by using a dental design software program (Exocad Dental CAD2.2, Exocad GmbH, Darmstadt, Germany) with $30 \mu \mathrm{m}$ cement space gap [26]. This 
design was saved as the reference scan STL file (RS-STL), which was then used to fabricate 3D-printed $(n=30)$ and milled (control) $(n=10)$ molar crowns.

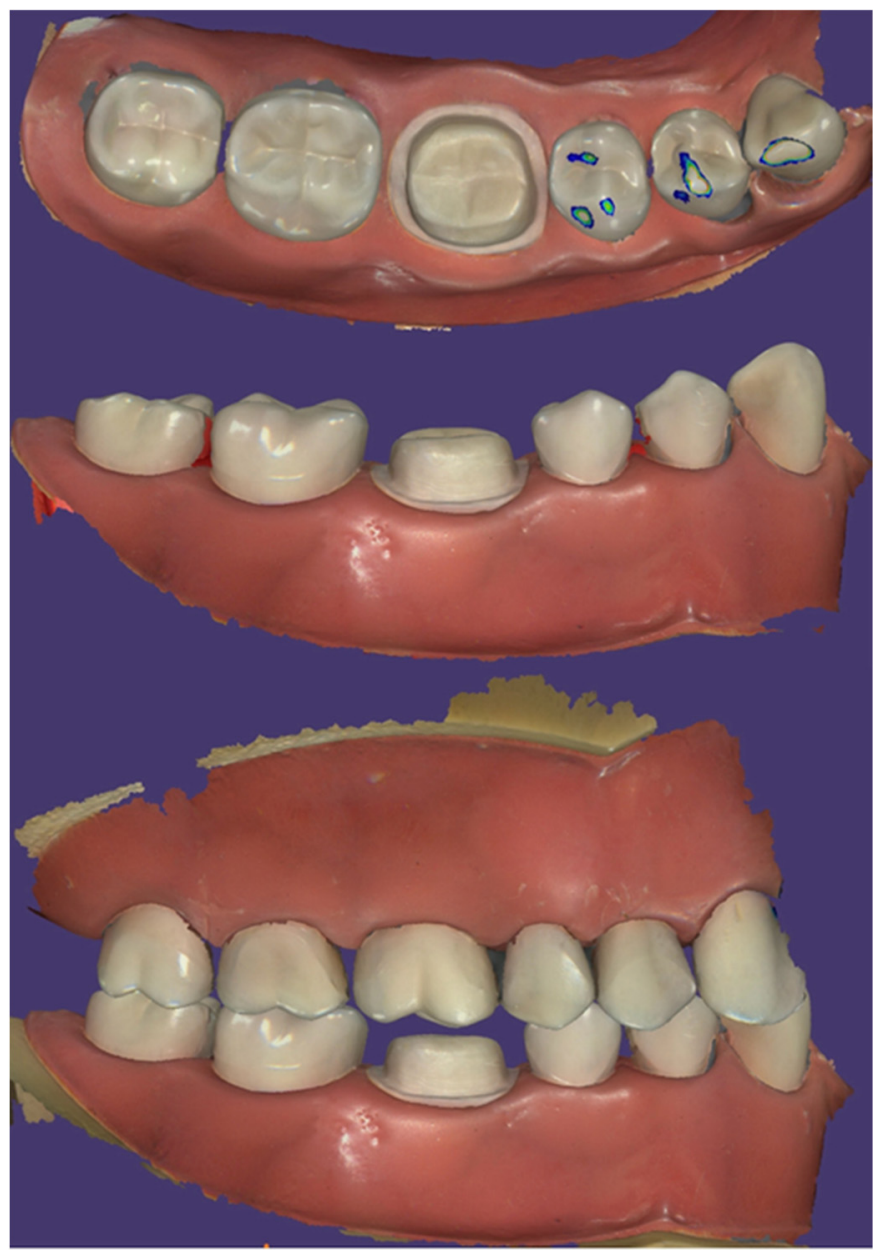

Figure 1. Mandibular right first molar preparation.

\subsection{Crown Fabrication}

Three different layer thicknesses $(20 \mu \mathrm{m}, 50 \mu \mathrm{m}$, and $100 \mu \mathrm{m})$ were used to print the crowns ( $n=10$ per layer thickness). First, the RS-STL file of the crown was imported to DLP software (MoonRay S100, SprintRay Inc, Los Angeles, CA, USA) to arrange the build angle and support configuration. As recommended by the manufacturer of the printing resin material (Nextdent Crown and Bridge Micro Filled Hybrid-MFH, C\&B; 3D systems, Soesterberg, The Netherlands), the occlusal surface of the crown was angled $45^{\circ}$ from the print area for improved occlusal surface details. The semiautomatically created support structures were checked and supports that were automatically created on the margin area and fitting surfaces of the crowns were manually eliminated. Then, this configuration was duplicated 10 times and 10 identical crown configurations were arranged in the build platform of the DLP printer (MoonRay S100 Software, SprintRay Inc, Los Angeles, CA, USA) to print all crowns in the same configuration. This configuration was further saved for 3 different layer thicknesses to print the crowns in identical configuration, but by using different layer thicknesses. The crowns were printed with the DLP printer (MoonRay S100, SprintRay Inc, Los Angeles, CA, USA) and an interim printing resin material (N1 shade, Nextdent Crown and Bridge Micro Filled Hybrid-MFH, C\&B; 3D systems, Soesterberg, The Netherlands, Lot: XH312N21) by using $20 \mu \mathrm{m}, 50 \mu \mathrm{m}$, or $100 \mu \mathrm{m}(n=10)$ layer thickness. According to the manufacturer, the printing material has 100-130 MPa flexural strength, 2400-2600 MPa flexural modulus, $\leq 70 \mu \mathrm{g} / \mathrm{mm}^{3}$ sorption, and $\leq 15.5 \mu \mathrm{g} / \mathrm{mm}^{3}$ solubility. 
The DLP printer has UV DLP projector, LED-based light source, and $405 \mathrm{~nm}$ blue-violet light resin curing unit. After printing, the printed crowns were removed from the platform by using a putty knife, ultrasonically rinsed for $5 \mathrm{~min}$ (first $3 \mathrm{~min}$ then $2 \mathrm{~min}$ ) in $96 \%$ clean alcohol solution (Alcohol isopropilico, Quimi Klean, Mexico City, Mexico) according to the manufacturers' recommendations. After ensuring that the crowns were dry and free of alcohol residue, they were postpolymerized by using an ultraviolet polymerizing unit (SprintRay Procure Model SRP1811A, SprintRay Inc, Los Angeles, CA, USA) (405 nm LED arrays) for $30 \mathrm{~min}$ (Figure 2).
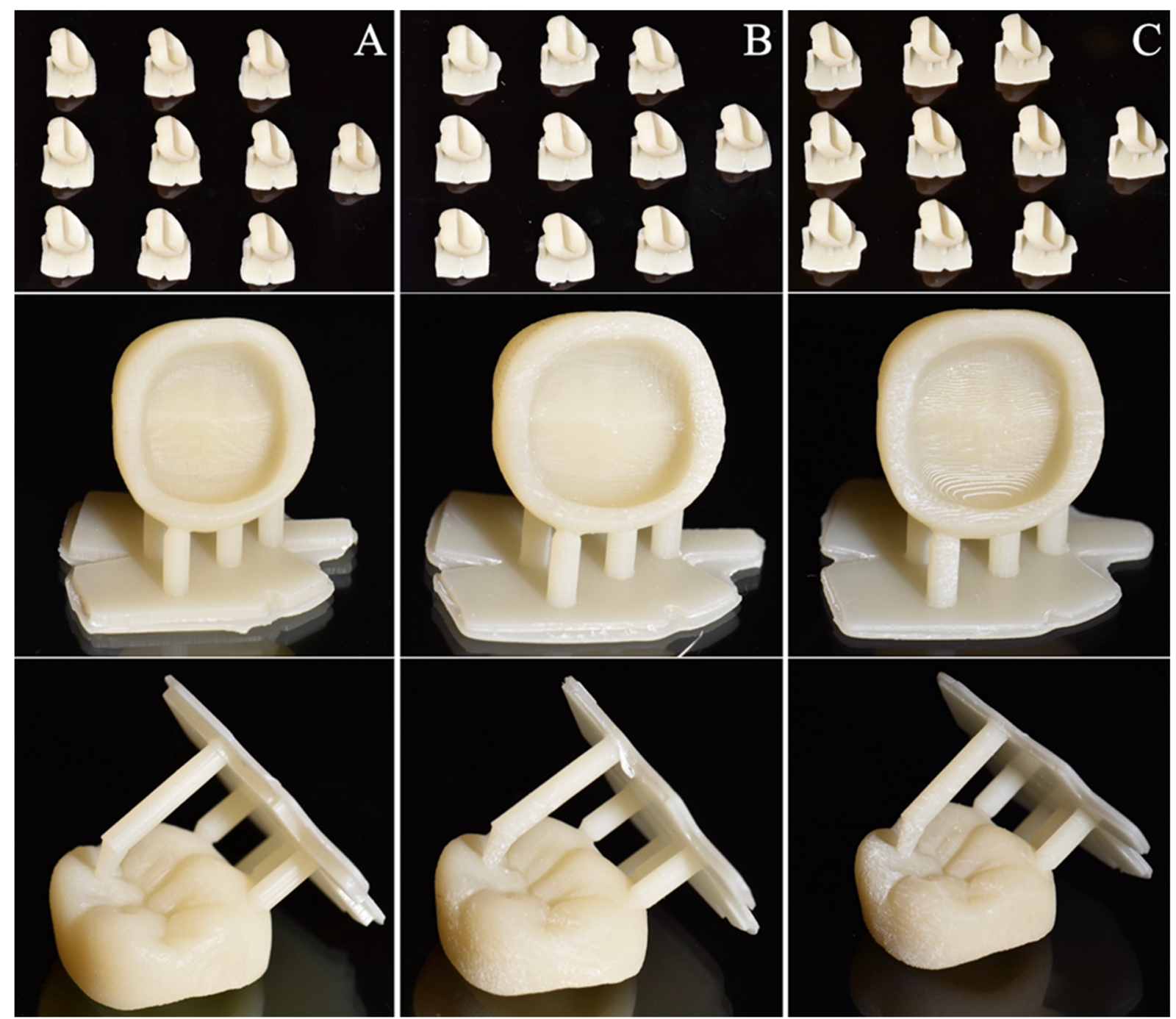

Figure 2. 3D-printed interim crowns ((A): $20 \mu \mathrm{m}$ crowns; (B): $50 \mu \mathrm{m}$ crowns; (C): $100 \mu \mathrm{m}$ crowns).

The support structures were cut and trimmed after cooling and the surface was gently smoothened to prevent errors during the alignment procedure.

In the milling technique, crowns were milled (Wieland Zenotec mini, V6.12.04, Wieland Dental + Technik GmbH \& Co.KG, Pforzheim, Germany) from a polymethyl methacrylate (PMMA) block (A2 shade, Lot number: HL201104, Upcera, Shenzhen Upcera Dental Technology Co. Ltd., Shenzen, Guandong, China). The designed STL file was inserted in the block to mill 10 identical crowns. The support structures were cut and trimmed after milling, and the support surfaces were gently smoothened. All crown fabrication processes were performed by one operator (G. Ç). 


\subsection{Crown Analysis}

All crowns were examined under optical magnification loupe $(3.5 \times)$ to ensure that they were free from any defects and no adjustments were made on the inner surfaces of the crowns [26]. Crowns were then kept in dry and lightproof boxes to scan within $48 \mathrm{~h}$ after the fabrication. First, the scanner was calibrated and then the printed and milled crowns were scanned by using an intraoral scanner (Medit i500 v. 1.2.1, Medit, Seoul, Korea) by the same operator (G. Ç) and the scan files were converted to STL files (test-scan STL). During the scan, the crowns were hold with small tweezers and as the intraoral scanner utilized has a filter for colors, the parts in contact with the tweezers were scanned afterwards.

For the deviation analysis, root mean square (RMS) was used to indicate how far the deviations were from zero between the 2 different datasets [32]. A low RMS value indicated a high degree of 3D matching of the superimposed data, which translated to high trueness [33]. First, test-scan STL files and designed crown STL file (RS-STL) were imported into a software (Medit Link, Medit, Seoul, Korea). Compare tool (Medit Compare v1.1.1.61, Medit, Seoul, Korea) of the software, which has an automatic alignment tool was used for the superimposition, virtually separation of the surfaces, and RMS calculation. For the superimposition, RS-STL was moved to the reference data and test-scan STL was moved to the target data by using the alignment tool of the software. Then, manual alignment tool of the software was selected and 3 reference points; central fossa, mesial and distal triangular fossae were selected both in the reference and target data. Test-scan STL files were then superimposed over the RS-STL file (Figure 3).

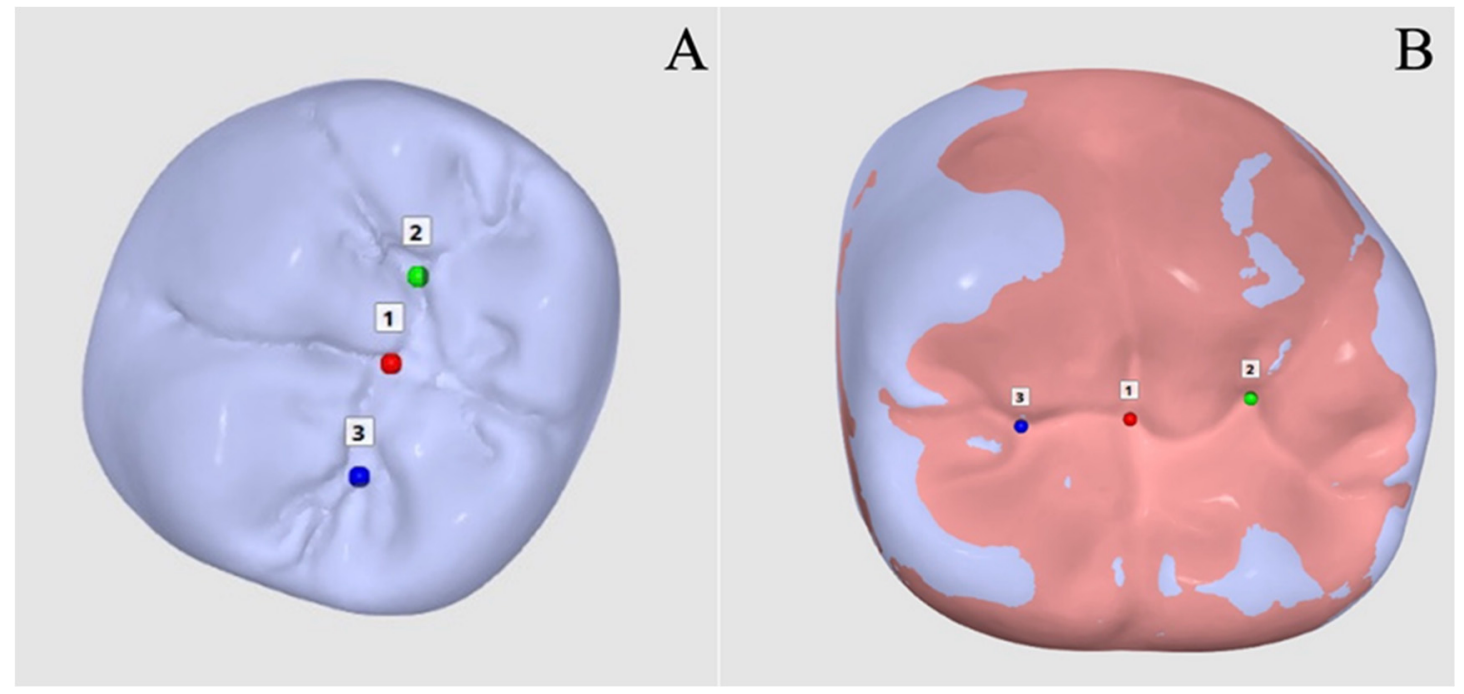

Figure 3. (A): Reference points determined for the superimposition of STL files (1: Central fossa; 2: Distal triangular fossa; 3: Mesial triangular fossa), (B): Superimposition of the Test-scan STL over the RS-STL by using these points.

To generate color maps to represent the 3D deviation, deviation display mode of the software was used. The maximum/minimum critical (nominal) values were set at $+50 /-50 \mu \mathrm{m}$ with a tolerance range of $+10 /-10 \mu \mathrm{m}$, respectively [34]. After the superimposition, color-difference maps were created to compare the test scan STL file and the RS-STL for the overall RMS, which includes all surfaces of the crowns. The software automatically calculated the RMS from the color-difference maps, without the need for an additional formula. For the RMS of external, intaglio, marginal area, and intaglio occlusal surfaces of the crowns, the test-scan STL files and the RS-STL file were imported again, and these surfaces were virtually separated both in test-scan STL files and RS-STL file [34] dividing crowns into 4 different parts by using the edit mode of the software. After separation, the superimposition was done once again for each surface (external, intaglio, marginal area, and intaglio occlusal surfaces) of each crown by using automatic alignment mode of the software, and the color-difference maps were generated for those surfaces and the RMS 
values were automatically calculated (Figure 4). The areas with deviations exceeding the scale utilized were presented as gray by the software. However, all areas were included in the RMS calculation.
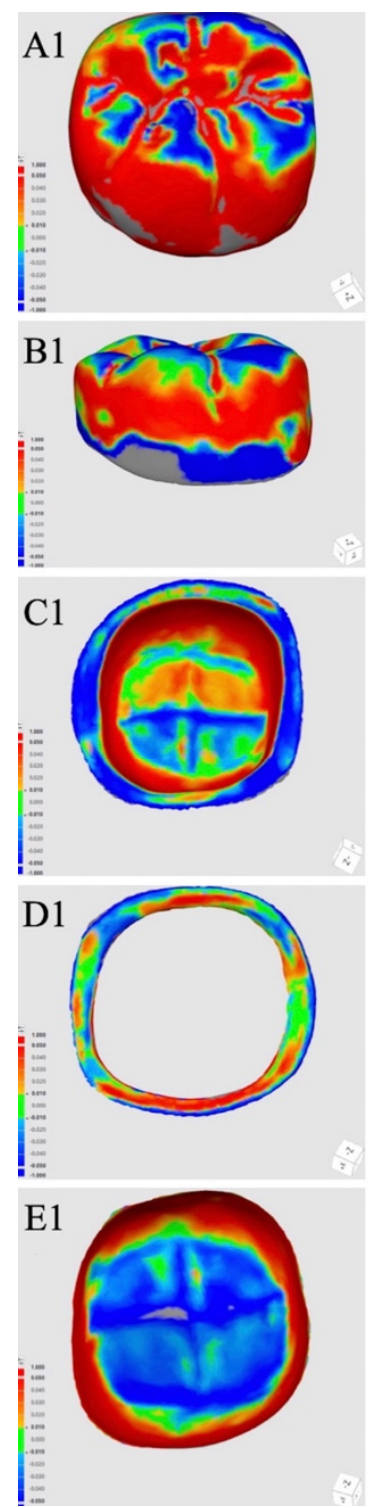
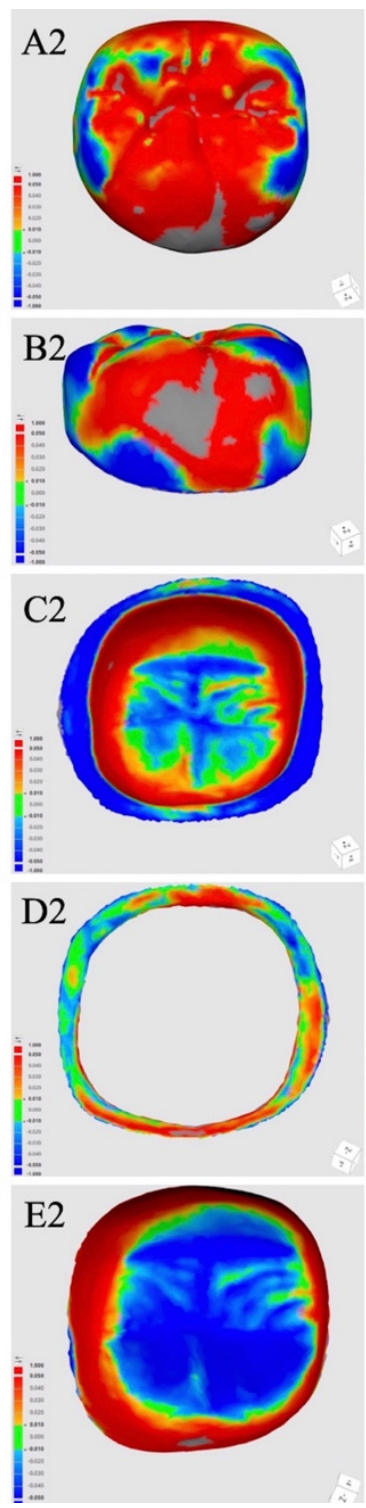
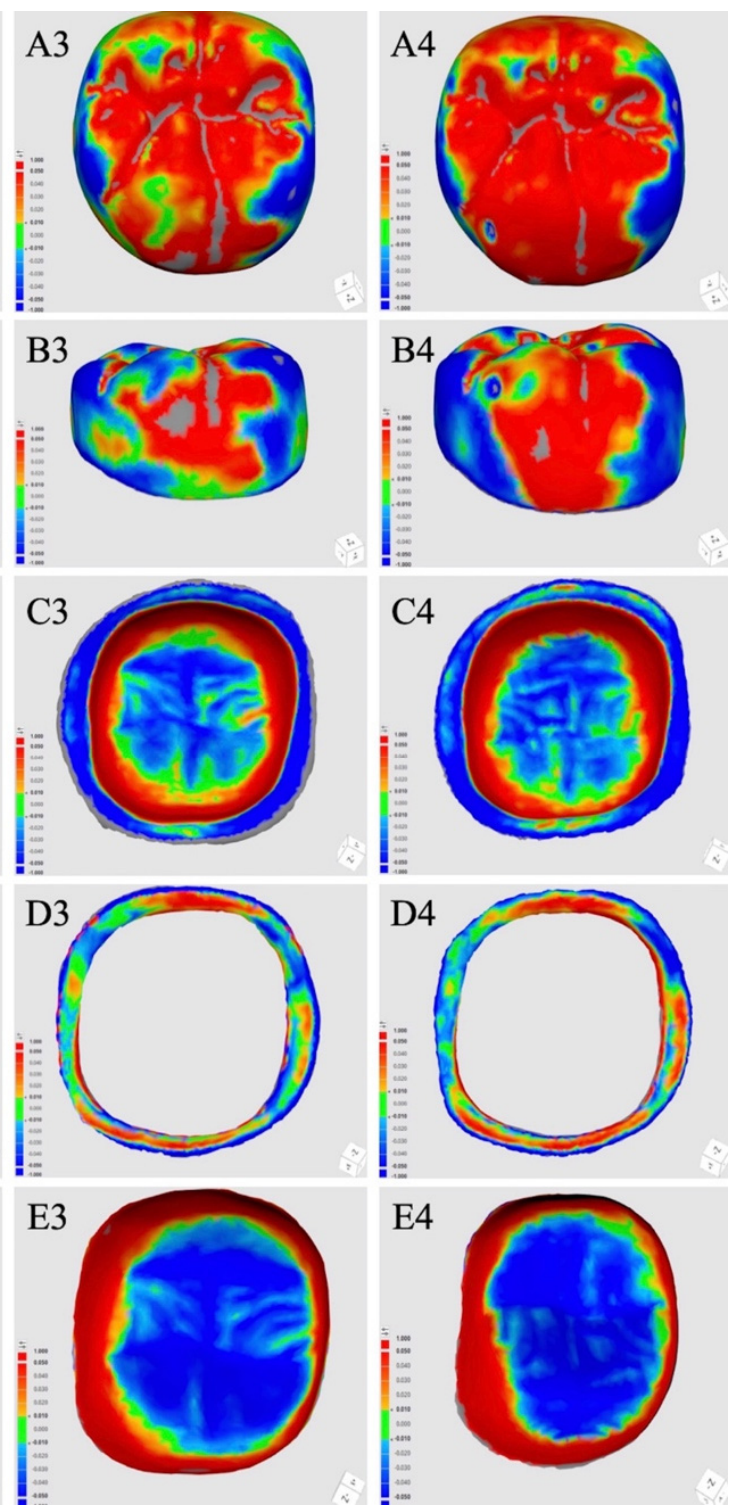
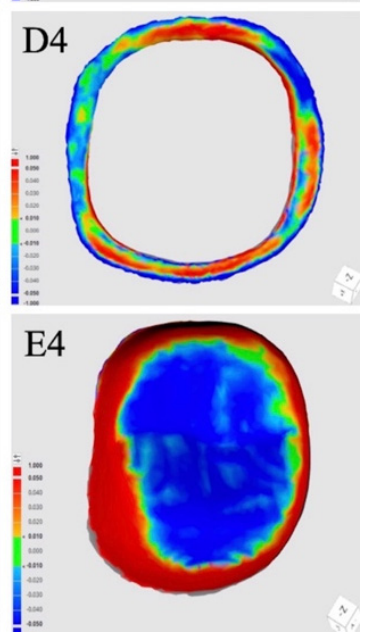

Figure 4. Color maps generated by the superimposition of the milled (1), $20 \mu \mathrm{m}(\mathbf{2}), 50 \mu \mathrm{m}(\mathbf{3})$, and $100 \mu \mathrm{m}(4)$ crown meshes over reference data ((A): Overall RMS; (B): External RMS; (C): Internal RMS; (D): Marginal RMS; (E): Intaglio Occlusal RMS).

For margin quality comparison, each crown was randomly numbered by an independent individual, and then visually examined with an optical microscope (Zeiss) under $\times 60$ magnification by a single operator (G.Ç.) who was blinded about the numbering, and a grading system from 1 to 3 was used as performed in a previous study [29]. Grade 1 crown margins indicated rough edges similar to layers. Grade 2 crown margins indicated slightly rough edges similar to waves. Grade 3 crown margins indicated smooth edges (Figure 5). Margin quality was examined at each margin location (buccal, lingual, mesial, and distal) of each crown, and the average was calculated for each printed or milled crown. 

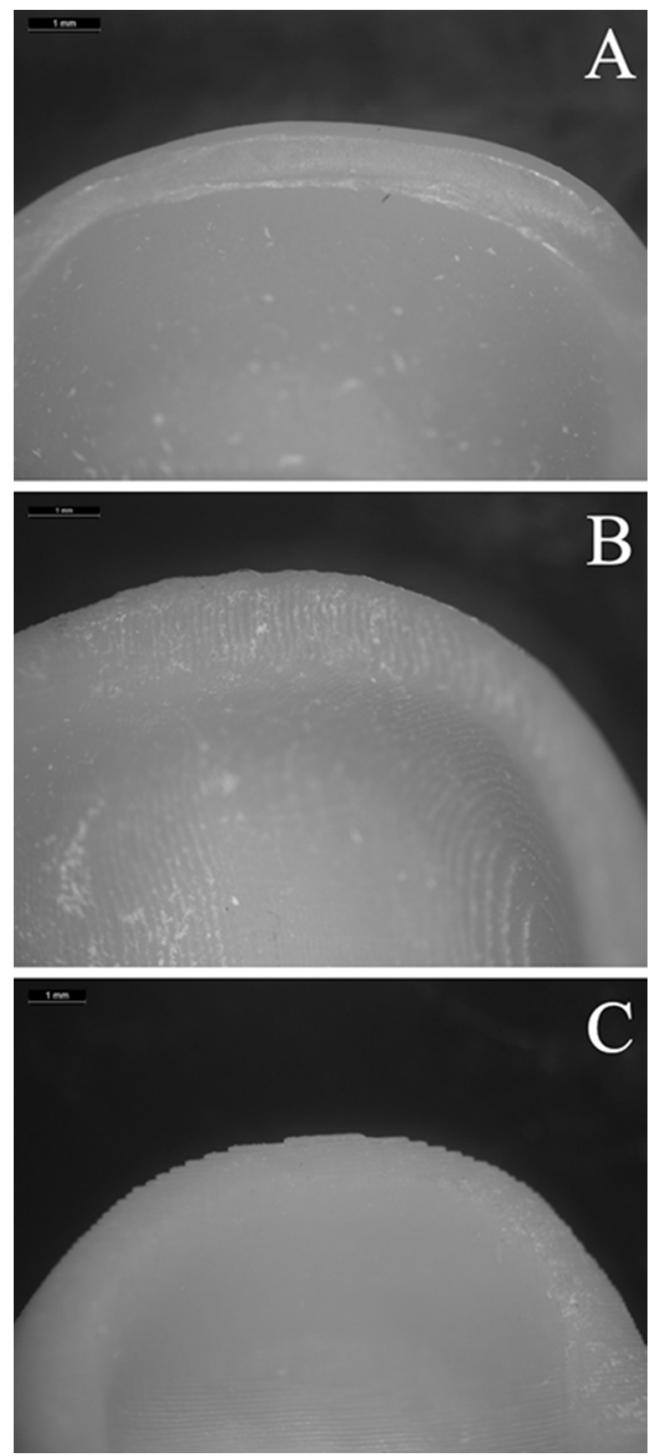

Figure 5. Margins according to the grading system ((A): Grade 3; (B): Grade 2; (C): Grade 1).

\subsection{Statistical Analysis}

The statistical evaluation of the data was performed by using the statistical software R. Normality assumption was verified using the Shapiro Wilks test. Difference in RMS values between fabrication technique within each area of measurement, difference in average quality rating between fabrication technique, and difference in quality rating between margin location for each fabrication technique was analyzed by using the one-way analysis of variance (ANOVA). Additionally, pairwise comparisons within the groups were analyzed with Tukey HSD Post-Hoc analysis $(\alpha=0.05)$.

\section{Results}

One-way ANOVA results of the RMS values of each surface are presented in Table 1, and Figure 6 illustrates the RMS at each measured surface for control and different layerthickness groups. 
Table 1. Mean RMS $(\mu \mathrm{m})$ values \pm standard deviations for milled and 3D-printed interim crowns. Different superscript lowercase letters in same column indicate significant differences among groups $(p<0.05)$.

\begin{tabular}{|c|c|c|c|c|c|}
\hline Layer Thickness & Overall RMS $(\mu \mathrm{m})$ & External RMS $(\mu \mathrm{m})$ & Intaglio RMS $(\mu \mathrm{m})$ & Marginal RMS ( $\mu \mathrm{m})$ & $\begin{array}{l}\text { Intaglio Occlusal } \\
\text { RMS }(\mu \mathrm{m})\end{array}$ \\
\hline Control (Milled) & $64.5 \pm 10.94^{a}$ & $54 \pm 21.29^{a}$ & $32.6 \pm 15.01^{\mathrm{a}}$ & $11.3 \pm 14.36^{\mathrm{a}}$ & $31.5 \pm 6.92^{a}$ \\
\hline $20 \mu \mathrm{m}$ & $56.1 \pm 10.7^{\mathrm{a}}$ & $59.4 \pm 10.7^{\mathrm{a}}$ & $49.9 \pm 12.13^{\mathrm{ab}}$ & $14.9 \pm 9.57^{\mathrm{a}}$ & $33.4 \pm 2.22^{a b}$ \\
\hline $50 \mu \mathrm{m}$ & $53.3 \pm 9.3^{\mathrm{a}}$ & $48.5 \pm 13.67^{\mathrm{a}}$ & $45.4 \pm 15.75^{\mathrm{ab}}$ & $9.1 \pm 8.02^{\mathrm{a}}$ & $34.7 \pm 1.83^{\mathrm{ab}}$ \\
\hline $100 \mu \mathrm{m}$ & $61.3 \pm 15.31^{a}$ & $62.4 \pm 18.21^{\mathrm{a}}$ & $52.8 \pm 17.32^{b}$ & $14.6 \pm 9.94^{\mathrm{a}}$ & $41.5 \pm 12.55^{b}$ \\
\hline$p$ values & 0.145 & 0.263 & 0.026 & 0.576 & 0.024 \\
\hline
\end{tabular}

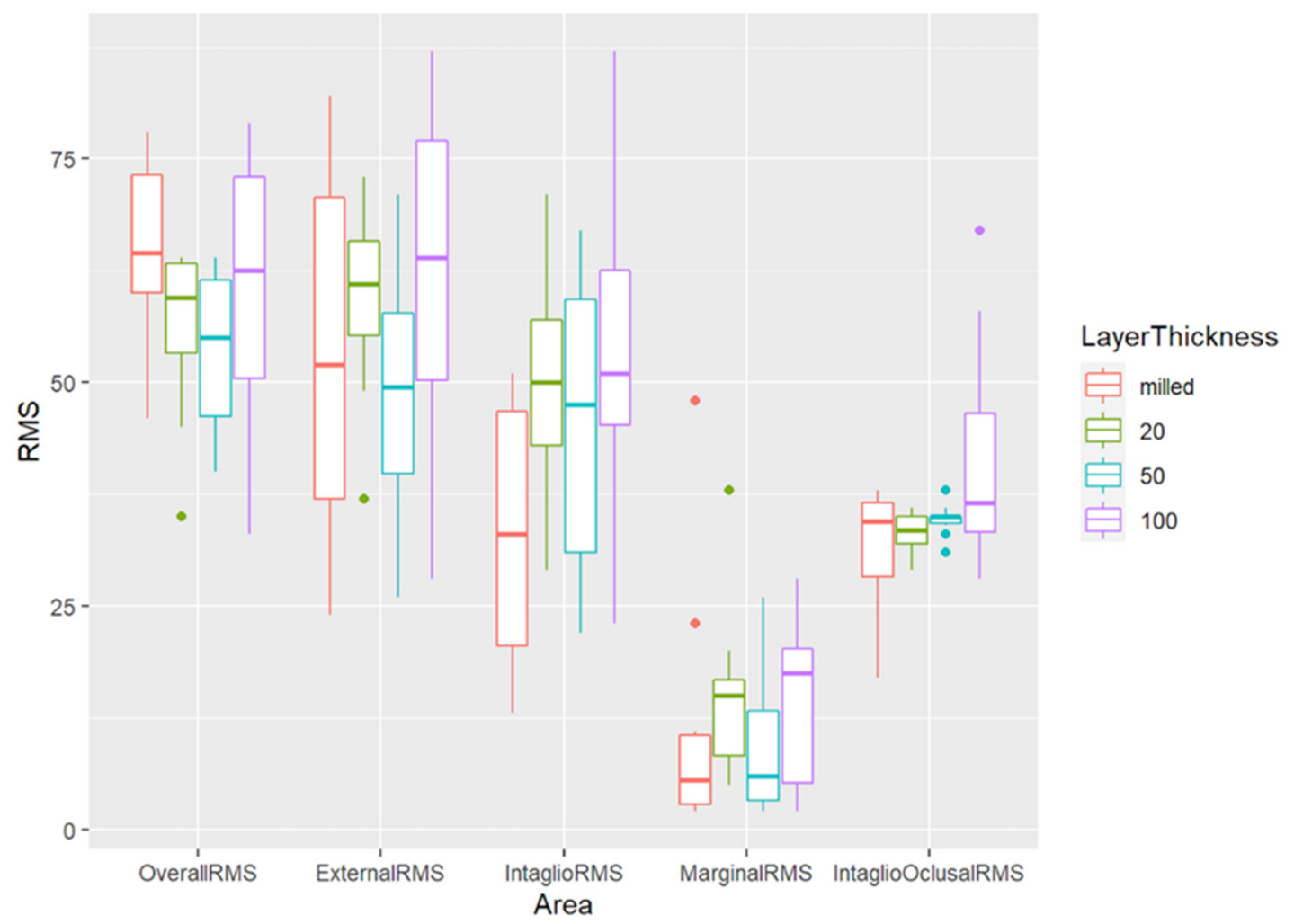

Figure 6. Box-plot graph of the RMS values of milled and 3D-printed interim crowns according to different surfaces.

Significant differences were observed among fabrication techniques for intaglio and intaglio occlusal surface RMS values $(p \leq 0.026)$. Milled crowns presented significantly lower RMS values than $100 \mu \mathrm{m}$ crowns at both intaglio ( $p=0.025$, estimated difference in means: $-20.2 \mu \mathrm{m})$ and intaglio occlusal $(p=0.021$, estimated difference in means: $-10 \mu \mathrm{m})$ surfaces. Every other pairwise comparison for intaglio $(p \geq 0.251)$ and intaglio occlusal ( $p \geq 0.178$ ) surfaces were nonsignificant.

Average margin quality of the crowns showed significant differences (Figure 7); based on the 3-point scale, milled crowns presented higher quality than the others $(p<0.001 \mathrm{vs} .20 \mu \mathrm{m}$, estimated difference in means: 1.25 points; $p=0.001$ vs. $50 \mu \mathrm{m}$, estimated difference in means: 0.68 points; and $p<0.001$ vs. $100 \mu \mathrm{m}$, estimated difference in means: 1.53 points). 


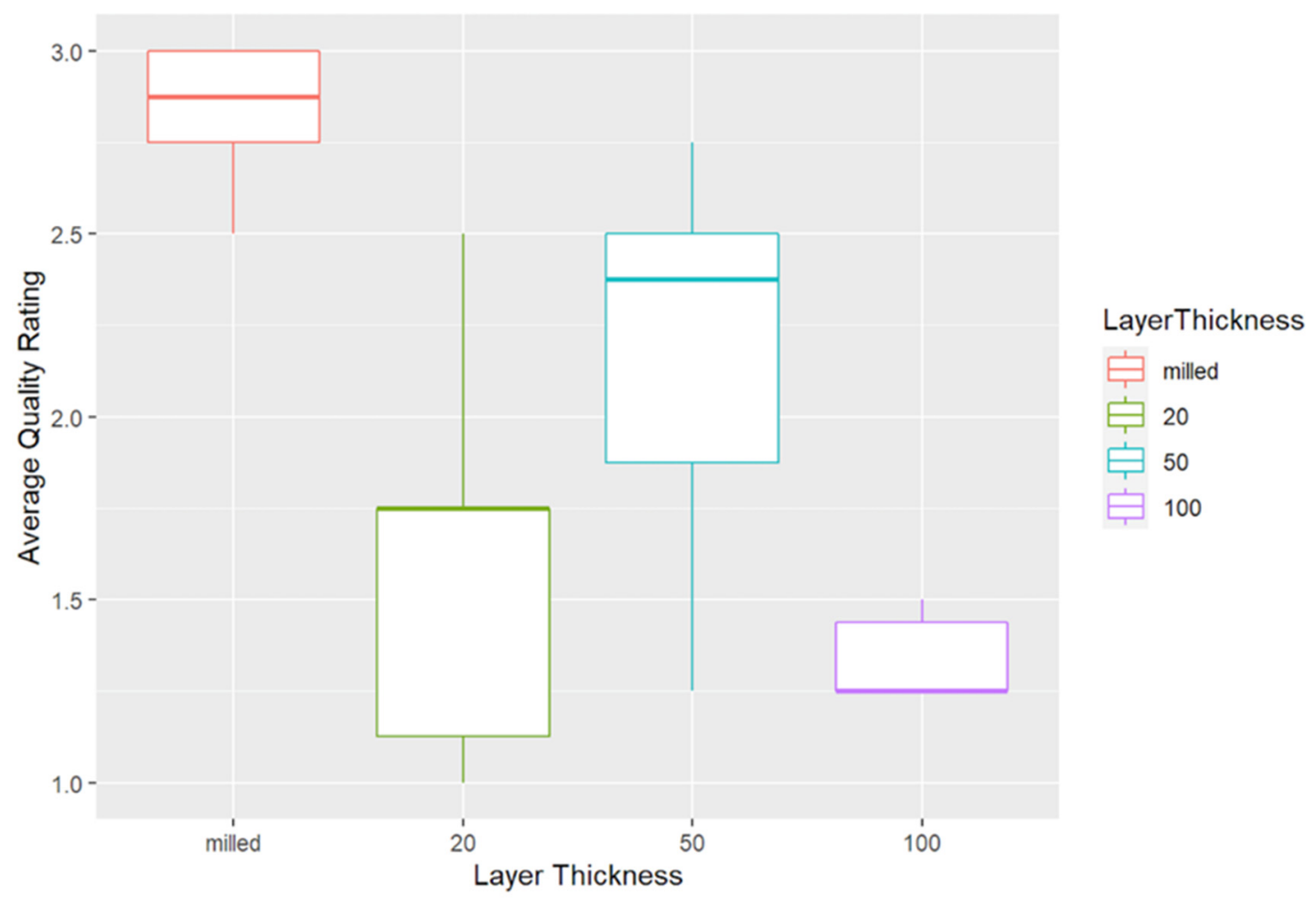

Figure 7. Average margin quality of all groups, evaluated by using a 3-point scale, ranging from 1 (worst marginal quality) to 3 (best marginal quality).

The margin quality of $50 \mu \mathrm{m}$ crowns was higher than that of $20 \mu \mathrm{m}(p=0.006$, estimated difference in means: 0.58 points) and $100 \mu \mathrm{m}(p<0.001$, estimated difference in means: 0.85 points) crowns. The difference between $20 \mu \mathrm{m}$ crowns and $100 \mu \mathrm{m}$ crowns was nonsignificant $(p=0.348)$. Table 2 summarizes the $p$ values when the Tukey HSD test was applied to analyze the effect of margin location on the margin quality within each fabrication technique.

Table 2. $p$ values for the pairwise comparison between different margin locations for milled and 3D-printed interim crowns. $p<0.05$ indicate significant differences between locations.

\begin{tabular}{ccccccc}
\hline & \multicolumn{5}{c}{ Locations } \\
\hline Layer Thickness & Buccal-Lingual & Buccal-Mesial & Buccal-Distal & Lingual-Mesial & Lingual-Distal & Mesial-Distal \\
\hline Control (Milled) & 0.005 & 0.03 & 0.005 & 0.885 & $>0.05$ & 0.885 \\
$20 \mu \mathrm{m}$ & 0.121 & 0.762 & 0.988 & 0.566 & 0.223 & 0.914 \\
$50 \mu \mathrm{m}$ & 0.765 & 0.765 & 0.988 & $>0.05$ & 0.915 & 0.915 \\
$100 \mu \mathrm{m}$ & $<0.001$ & 0.831 & 0.831 & $<0.001$ & $<0.001$ & $>0.05$ \\
\hline
\end{tabular}

No significant differences were found between the quality of the margins at different locations for $20 \mu \mathrm{m}(p \geq 0.121)$ and $50 \mu \mathrm{m}(p \geq 0.765)$ crowns. However, margin quality of milled $(p=0.002)$ and $100 \mu \mathrm{m}(p<0.001)$ crowns were significantly affected by the margin location. The mesial, distal, and lingual margin quality of the milled crowns was similar ( $p \geq 0.885)$, while buccal margin quality was inferior to that at other locations $(p \leq 0.03)$. For the $100 \mu \mathrm{m}$ crowns, lingual margin quality was higher compared with other locations $(p<0.001)$; the differences among other locations were nonsignificant $(p \geq 0.831)$. The margin quality in control and each layer thickness groups according to the margin location is presented in Figure 8. 


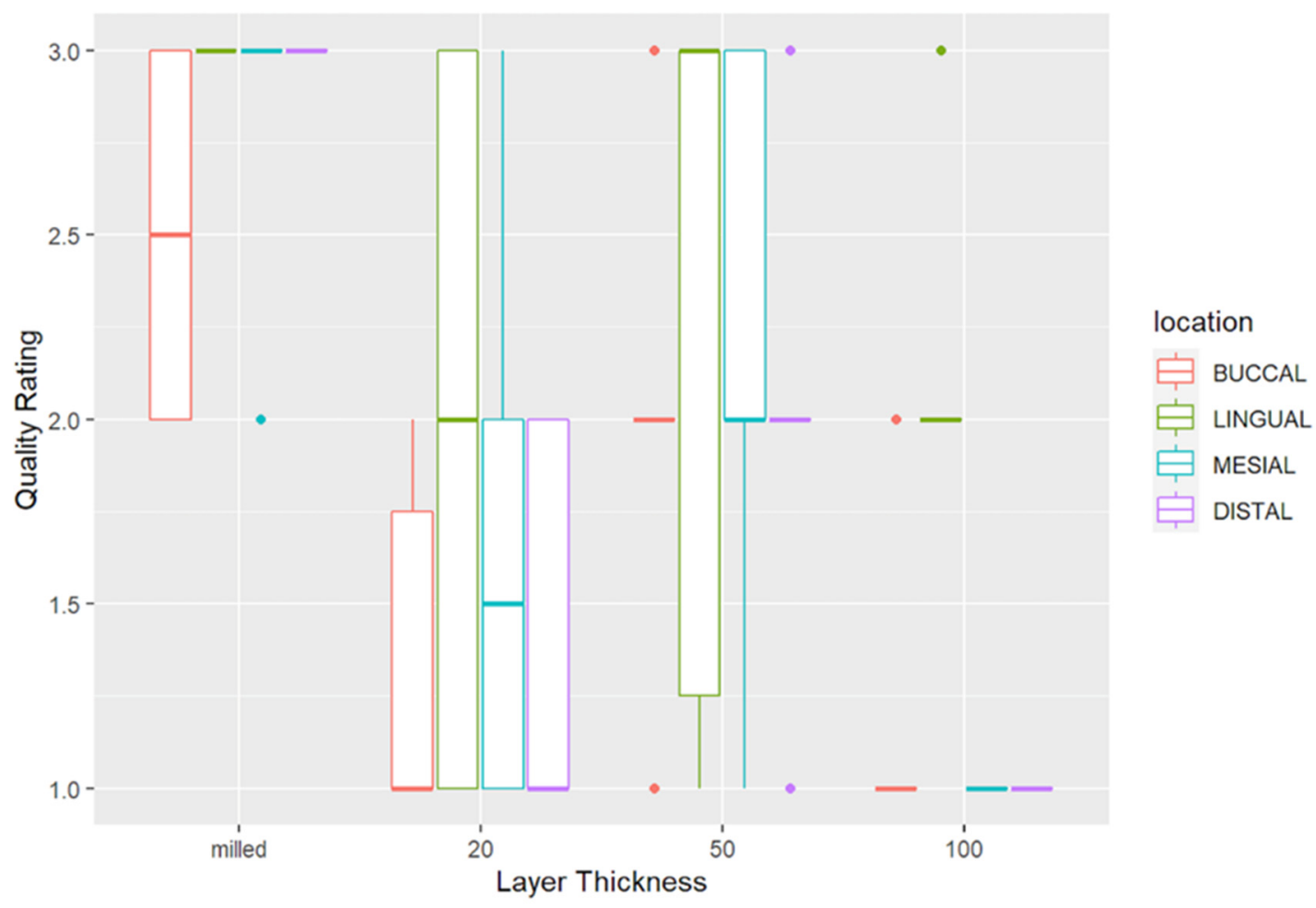

Figure 8. Margin quality of groups according to margin location, evaluated by using a 3-point scale that ranged from 1 (worst marginal quality) to 3 (best marginal quality).

\section{Discussion}

Significant differences in terms of trueness were found comparing the $100 \mu \mathrm{m}$ printing layer thickness to other groups. Therefore, the first null hypothesis was rejected. The best margin quality was found in milled crowns, followed by the $50 \mu \mathrm{m}$ layer thickness group. Accordingly, the second null hypothesis was rejected.

In terms of trueness, the present study showed that 3D-printed interim crowns, printed with a layer thickness of 20 or $50 \mu \mathrm{m}$, are similar to the milled interim crowns, which are currently used routinely. Similar results have been reported also for 3D-printed ceramic crowns $[15,35]$. The effect of the layer thickness on the trueness of 3D printed casts and complete dentures has been demonstrated in previous studies [30,36]. Those studies demonstrated the highest trueness when a layer thickness of $100 \mu \mathrm{m}$ was used, whereas the $100 \mu \mathrm{m}$ layer thickness resulted in the lowest trueness in the present study. The main difference between those and the present study may be due to the nature of the objects printed. Neither casts nor dentures have as thin and tapered margins as crowns have, instead, they have large plain and round surfaces [36]. When the layer thickness is too small, discrepancies can occur, especially with such thin margins [30]. The combination of thin layer thickness and thin margins could also be an explanation for the fact that the trueness seems to be slightly higher in the $50 \mu \mathrm{m}$ group compared to the $20 \mu \mathrm{m}$ group, although this difference was not statistically significant. It should be noted that the aforementioned scoping review on complete denture fabrication included various studies [36], which applied varying settings for the 3D-printing, and therefore, the deviations in trueness may not be attributed to the layer thickness alone. A study, which showed that layer thickness did not affect the trueness of printed models when $100 \mu \mathrm{m}$ was applied, still recommended the use of $100 \mu \mathrm{m}$ layer thicknesses due to the economic advantages as the printing time is shortened [37]. However, the time factor may be less important when small restorations such as crowns are fabricated. Considering the effect of the layer thickness on trueness at thin surfaces such as crown margins [30], high layer thickness may be expected to result in low trueness, which was confirmed by lower trueness and marginal quality found with 
the $100 \mu \mathrm{m}$ group in the present study. Although a previous study has shown that the marginal fit of 3D-printed crowns is within a clinically acceptable range, and that there is no difference between 3D-printed and milled crowns [38], significant differences in the margin quality were found in the present study. The marginal quality in the present study was evaluated by a 3-point scale instead of absolute values, indicating worse margin quality of the 3D-printed crowns irrespective of the layer thickness. Interestingly, the margin quality was not influenced by margin location in $20 \mu \mathrm{m}$ and $50 \mu \mathrm{m}$ groups, but in milled and $100 \mu \mathrm{m}$ groups. The significantly worse margin quality at the buccal aspect of the milled group may be due to the slightly narrower preparation margin on the distobuccal side. During the milling process, defects may occur at thin crown margins [39]. Hypothetically, the preparation margin could also be the reason for the better marginal quality at the lingual crown margin in the $100 \mu \mathrm{m}$ group. The lingual aspect of the margin preparation was the most uniform, which might have allowed the crown to be fabricated accurately even with the largest layer thickness of $100 \mu \mathrm{m}$. A large layer thickness might have a negative effect on the margin quality, especially with varying crown margin thicknesses. The fact that the margins of the prepared tooth were not uniform at all aspects is a limitation of the present study. Future studies are necessary to determine the effect of layer thickness on trueness and margin quality.

The reference data set can be recorded with a laboratory scanner, or more precisely with a high-precision optical or tactile industrial scanner [40]. However, because such scanners cannot be used intraorally, the reference data set was taken with an intraoral scanner. The intraoral scanner used has a software that enables immediate scanning of the fabricated restoration and the analysis of the trueness of the restoration comparing with the design STL. Adequate scan accuracy with the intraoral scanner used has been demonstrated in previous studies on single crowns [41]. Generally, intraoral scanners have demonstrated sufficient accuracy especially when scanning partial arches, as executed in the present study [41]. Since the reference data set was used to fabricate all crowns, potential errors during scanning would be expected to affect all groups similarly and therefore, can be considered negligible for its effect on the comparisons aimed. The trueness was analyzed by the calculation of RMS differences between the test and reference datasets. Calculating RMS differences is the most commonly applied trueness analysis in digital dentistry [42]. However, the effect of different software programs to calculate RMS values between corresponding datasets is not clear [43-45]. The influence of the build angle on the fabrication of 3D-printed crowns has been shown in various studies [14,18,25,26,29]. The build angle of $45^{\circ}$ was used to print the crowns based on the recommendation by the manufacturer. A $45^{\circ}$ build angle is similar to $135^{\circ}$ build angle in terms of crown orientation during the fabrication, except that the $45^{\circ}$ angle assumes a buccal crown orientation while $135^{\circ}$ angle assumes a lingual crown orientation. The effect of build angle on crown accuracy when DLP technology is used was previously investigated and the highest accuracy was achieved when $135^{\circ}$ angle was used [18].

Due to the pilot nature of the present study, no sample size calculation could be performed. The sample size was based on earlier studies, focusing on the 3D-printing accuracy $[14,46]$ and enabled the detection of statistically significant differences in terms of trueness and marginal quality. One of the main limitations of the present study is that only one material was used for the fabrication of milled and 3D-printed crowns. Since previous studies have shown that the material has a significant influence on crown accuracy [47], the present study findings are not directly applicable to other materials. Nevertheless, the present study is the first of its kind indicating the influence of layer thickness on the accuracy of $3 \mathrm{D}$ printed resin crowns. The quantification of the marginal gap size was not performed in the present study. Since there was no difference between the milled and 3D-printed crowns when a layer thickness of $20 \mu \mathrm{m}$ or $50 \mu \mathrm{m}$ was used, a major difference in terms of marginal gap size would not be expected between these groups, however, marginal gap measurements can be performed in future studies to see how milling/printing trueness translates to marginal quality. The fact that the margin quality 
was only assessed by one observer is another weak point. Since the observer was blinded during the evaluation, it can at least be assumed that the risk of bias (e.g., by personal preferences) was minimized [48].

\section{Conclusions}

Considering limitations of the present study, it can be concluded that the trueness and marginal quality of 3D-printed interim crowns was influenced by the printing layer thickness. For improved trueness and margin quality for interim crowns using the applied materials and settings, a printing layer thickness of 20 or $50 \mu \mathrm{m}$ may be preferable over $100 \mu \mathrm{m}$.

Author Contributions: Conceptualization, G.Ç., A.R.C. and B.Y.; methodology, G.Ç. and A.R.C.; software, G.Ç. and M.B.D.; validation, G.Ç., M.B.D. and B.Y.; formal analysis, G.Ç. and W.-E.L.; investigation, G.Ç.; resources, A.R.C.; data curation, W.-E.L., M.B.D. and S.A.-A.; writing-original draft preparation, M.B.D. and S.A.-A.; writing-review and editing, M.B.D., S.A.-A., M.S. and B.Y.; visualization, G.Ç.; supervision, M.S. and B.Y.; project administration, G.Ç. and B.Y., funding acquisition, none. All authors have read and agreed to the published version of the manuscript.

Funding: The authors would like to thank Laboratorio Innovando (Mexico City, Mexico) for their support in milling crowns and 3D Sequence Digital Laboratorio (Mexico City, Mexico) for their support in printing machine. The materials used in the present study were self-funded.

Data Availability Statement: Data available on request. The data presented in this study are available on request from the corresponding author. The data are not publicly available due to ongoing research using the data.

Acknowledgments: The authors would like to thank Laboratorio Innovando (Mexico City, Mexico) for their support in milling crowns and 3D Sequence Digital Laboratorio (Mexico City, Mexico) for their support in printing machine. The materials used in the present study were self-funded.

Conflicts of Interest: The authors declare no conflict of interest.

\section{References}

1. Liu, Y.; Ye, H.; Wang, Y.; Zhao, Y.; Sun, Y.; Zhou, Y. Three-dimensional analysis of internal adaptations of crowns cast from resin patterns fabricated using computer-aided design/computer-assisted manufacturing technologies. Int. J. Prosthodont. 2018, 31, 386-393. [CrossRef]

2. Kessler, A.; Hickel, R.; Reymus, M. 3D printing in dentistry-state of the art. Oper. Dent. 2020, 45, 30-40. [CrossRef]

3. Tahayeri, A.; Morgan, M.; Fugolin, A.P.; Bompolaki, D.; Athirasala, A.; Pfeifer, C.S.; Ferracane, J.L.; Bertassoni, L.E. 3D printed versus conventionally cured provisional crown and bridge dental materials. Dent. Mater. 2018, 34, 192-200. [CrossRef] [PubMed]

4. van Noort, R. The future of dental devices is digital. Dent. Mater. 2012, 28, 3-12. [CrossRef] [PubMed]

5. Dawood, A.; Marti Marti, B.; Sauret-Jackson, V.; Darwood, A. 3D printing in dentistry. Br. Dent. J. 2015, 219, 521-529. [CrossRef]

6. Muta, S.; Ikeda, M.; Nikaido, T.; Sayed, M.; Sadr, A.; Suzuki, T.; Tagami, J. Chairside fabrication of provisional crowns on FDM 3D-printed PVA model. J. Prosthodont. Res. 2020, 64, 401-407. [CrossRef] [PubMed]

7. Revilla-León, M.; Özcan, M. Additive manufacturing technologies used for processing polymers: Current status and potential application in prosthetic dentistry. J. Prosthodont. 2019, 28, 146-158. [CrossRef]

8. Salmi, M.; Paloheimo, K.S.; Tuomi, J.; Ingman, T.; Mäkitie, A. A digital process for additive manufacturing of occlusal splints: A clinical pilot study. J. R. Soc. Interface. 2013, 10, 20130203. [CrossRef]

9. Zeng, L.; Zhang, Y.; Liu, Z.; Wei, B. Effects of repeated firing on the marginal accuracy of Co-Cr copings fabricated by selective laser melting. J. Prosthet. Dent. 2015, 113, 135-139. [CrossRef]

10. Salmi, M.; Paloheimo, K.S.; Tuomi, J.; Wolff, J.; Mäkitie, A. Accuracy of medical models made by additive manufacturing (rapid manufacturing). J. Craniomaxillofac. Surg. 2013, 41, 603-609. [CrossRef]

11. Reyes, A.; Turkyilmaz, I.; Prihoda, T.J. Accuracy of surgical guides made from conventional and a combination of digital scanning and rapid prototyping techniques. J. Prosthet. Dent. 2015, 113, 295-303. [CrossRef] [PubMed]

12. Alharbi, N.; Wismeijer, D.; Osman, R.B. Additive manufacturing techniques in prosthodontics: Where do we currently stand? A critical review. Int. J. Prosthodont. 2017, 30, 474-484. [CrossRef] [PubMed]

13. Liu, Y.; Bai, W.; Cheng, X.; Tian, J.; Wei, D.; Sun, Y.; Di, P. Effects of printing layer thickness on mechanical properties of 3D-printed custom trays. J. Prosthet. Dent. 2020. [CrossRef]

14. Shim, J.S.; Kim, J.E.; Jeong, S.H.; Choi, Y.J.; Ryu, J.J. Printing accuracy, mechanical properties, surface characteristics, and microbial adhesion of 3D-printed resins with various printing orientations. J. Prosthet. Dent. 2020, 124, 468-475. [CrossRef]

15. Lerner, H.; Nagy, K.; Pranno, N.; Zarone, F.; Admakin, O.; Mangano, F. Trueness and precision of 3D-printed versus milled monolithic zirconia crowns: An in vitro study. J. Dent. 2021, 103792. [CrossRef] 
16. Zhang, Z.C.; Li, P.L.; Chu, F.T.; Shen, G. Influence of the three-dimensional printing technique and printing layer thickness on model accuracy. J. Orofac. Orthop. 2019, 80, 194-204. [CrossRef]

17. Son, K.; Lee, J.H.; Lee, K.B. Comparison of intaglio surface trueness of interim dental crowns fabricated with SLA 3D printing, DLP 3D printing, and milling technologies. Healthcare 2021, 9, 983. [CrossRef] [PubMed]

18. Osman, R.B.; Alharbi, N.; Wismeijer, D. Build angle: Does it influence the accuracy of 3D-printed dental restorations using digital light-processing technology? Int. J. Prosthodont. 2017, 30, 182-188. [CrossRef]

19. Peng, C.C.; Chung, K.H.; Ramos, V., Jr. Assessment of the adaptation of interim crowns using different measurement techniques. J. Prosthodont. 2020, 29, 87-93. [CrossRef]

20. Peng, C.C.; Chung, K.H.; Yau, H.T.; Ramos, V., Jr. Assessment of the internal fit and marginal integrity of interim crowns made by different manufacturing methods. J. Prosthet. Dent. 2020, 123, 514-522. [CrossRef] [PubMed]

21. Simoneti, D.M.; Pereira-Cenci, T.; Dos Santos, M.B.F. Comparison of material properties and biofilm formation in interim single crowns obtained by 3D printing and conventional methods. J. Prosthet. Dent. 2020. [CrossRef]

22. Mai, H.N.; Lee, K.B.; Lee, D.H. Fit of interim crowns fabricated using photopolymer-jetting 3D printing. J. Prosthet. Dent. 2017, 118, 208-215. [CrossRef] [PubMed]

23. Kim, Y.H.; Jung, B.Y.; Han, S.S.; Woo, C.W. Accuracy evaluation of 3D printed interim prosthesis fabrication using a CBCT scanning based digital model. PLoS ONE 2020, 15, e0240508. [CrossRef]

24. Davis, S.; O'Connell, B. The provisional crown. J. Ir. Dent. Assoc. 2004, 50, 167-172. [PubMed]

25. Alharbi, N.; Osman, R.; Wismeijer, D. Effects of build direction on the mechanical properties of 3D-printed complete coverage interim dental restorations. J. Prosthet. Dent. 2016, 115, 760-767. [CrossRef]

26. Alharbi, N.; Osman, R.B.; Wismeijer, D. Factors influencing the dimensional accuracy of 3d-printed full-coverage dental restorations using stereolithography technology. Int. J. Prosthodont. 2016, 29, 503-510. [CrossRef] [PubMed]

27. Yoo, S.Y.; Kim, S.K.; Heo, S.J.; Koak, J.Y.; Kim, J.G. Dimensional accuracy of dental models for three-unit prostheses fabricated by various 3D printing technologies. Materials 2021, 14, 1550. [CrossRef]

28. Çakmak, G.; Yilmaz, H.; Treviño, A.; Kökat, A.M.; Yilmaz, B. The effect of scanner type and scan body position on the accuracy of complete-arch digital implant scans. Clin. Implant. Dent. Relat. Res. 2020, 22, 533-541. [CrossRef] [PubMed]

29. Yu, B.Y.; Son, K.; Lee, K.B. Evaluation of intaglio surface trueness and margin quality of interim crowns in accordance with the build angle of stereolithography apparatus 3-dimensional printing. J. Prosthet. Dent. 2020. [CrossRef]

30. You, S.M.; You, S.G.; Kang, S.Y.; Bae, S.Y.; Kim, J.H. Evaluation of the accuracy (trueness and precision) of a maxillary trial denture according to the layer thickness: An in vitro study. J. Prosthet. Dent. 2021, 125, 139-145. [CrossRef]

31. Park, G.S.; Kim, S.K.; Heo, S.J.; Koak, J.Y.; Seo, D.G. Effects of Printing Parameters on the fit of implant-supported 3D printing resin prosthetics. Materials 2019, 12, 2533. [CrossRef] [PubMed]

32. Schaefer, O.; Watts, D.C.; Sigusch, B.W.; Kuepper, H.; Guentsch, A. Marginal and internal fit of pressed lithium disilicate partial crowns in vitro: A three-dimensional analysis of accuracy and reproducibility. Dent. Mater. 2012, 28, 320-326. [CrossRef] [PubMed]

33. International Organization for Standardization. ISO-5725-2. Accuracy (Trueness and Precision) of Measurement Methods and ResultsPart 2: Basic Method for the Determination of Repeatability and Reproducibility of a Standard Measurement Method; ISO: Geneva, Switzerland, 1994; Available online: http:/ / www.iso.org/iso/store.htm (accessed on 22 December 1994).

34. Wang, W.; Yu, H.; Liu, Y.; Jiang, X.; Gao, B. Trueness analysis of zirconia crowns fabricated with 3-dimensional printing. J. Prosthet. Dent. 2019, 121, 285-291. [CrossRef]

35. Baumgartner, S.; Gmeiner, R.; Schönherr, J.A.; Stampfl, J. Stereolithography-based additive manufacturing of lithium disilicate glass ceramic for dental applications. Mater. Sci. Eng. C. Mater. Biol. Appl. 2020, 116, 111180. [CrossRef]

36. Vilela Teixeira, A.B.; Dos Reis, A.C. Influence of parameters and characteristics of complete denture bases fabricated by 3D printing on evaluated properties: A scoping review. Int. J. Prosthodont. 2021. [CrossRef]

37. Dias Resende, C.C.; Quirino Barbosa, T.A.; Moura, G.F.; Piola Rizzante, F.A.; Mendonça, G.; Zancopé, K.; Domingues das Neves, F. Cost and effectiveness of 3-dimensionally printed model using three different printing layer parameters and two resins. J. Prosthet. Dent. 2021. [CrossRef] [PubMed]

38. Haddadi, Y.; Ranjkesh, B.; Isidor, F.; Bahrami, G. Marginal and internal fit of crowns based on additive or subtractive manufacturing. Biomater. Investig. Dent. 2021, 8, 87-91. [CrossRef]

39. Li, R.; Chen, H.; Wang, Y.; Sun, Y. Performance of stereolithography and milling in fabricating monolithic zirconia crowns with different finish line designs. J. Mech. Behav. Biomed. Mater. 2021, 115, 104255. [CrossRef]

40. Pan, Y.; Tsoi, J.K.H.; Lam, W.Y.H.; Pow, E.H.N. Implant framework misfit: A systematic review on assessment methods and clinical complications. Clin. Implant. Dent. Relat. Res. 2021, 23, 244-258. [CrossRef]

41. Zimmermann, M.; Ender, A.; Mehl, A. Local accuracy of actual intraoral scanning systems for single-tooth preparations in vitro. J. Am. Dent. Assoc. 2020, 151, 127-135. [CrossRef]

42. O'Toole, S.; Osnes, C.; Bartlett, D.; Keeling, A. Investigation into the accuracy and measurement methods of sequential 3D dental scan alignment. Dent. Mater. 2019, 35, 495-500. [CrossRef]

43. Pellitteri, F.; Brucculeri, L.; Spedicato, G.A.; Siciliani, G.; Lombardo, L. Comparison of the accuracy of digital face scans obtained by two different scanners. Angle Orthod. 2021, 91, 641-649. [CrossRef] 
44. Peroz, S.; Spies, B.C.; Adali, U.; Beuer, F.; Wesemann, C. Measured accuracy of intraoral scanners is highly dependent on methodical factors. J. Prosthodont. Res. 2021. [CrossRef] [PubMed]

45. Son, K.; Lee, W.S.; Lee, K.B. Effect of different software programs on the accuracy of dental scanner using three-dimensional analysis. Int. J. Environ. Res. Public Health 2021, 18, 8449. [CrossRef]

46. Alharbi, N.; Alharbi, S.; Cuijpers, V.; Osman, R.B.; Wismeijer, D. Three-dimensional evaluation of marginal and internal fit of 3D-printed interim restorations fabricated on different finish line designs. J. Prosthodont. Res. 2018, 62, 218-226. [CrossRef] [PubMed]

47. Papadiochou, S.; Pissiotis, A.L. Marginal adaptation and CAD-CAM technology: A systematic review of restorative material and fabrication techniques. J. Prosthet. Dent. 2018, 119, 545-551. [CrossRef] [PubMed]

48. Day, S.J.; Altman, D.G. Statistics notes: Blinding in clinical trials and other studies. BMJ 2000, 321, 504. [CrossRef] [PubMed] 